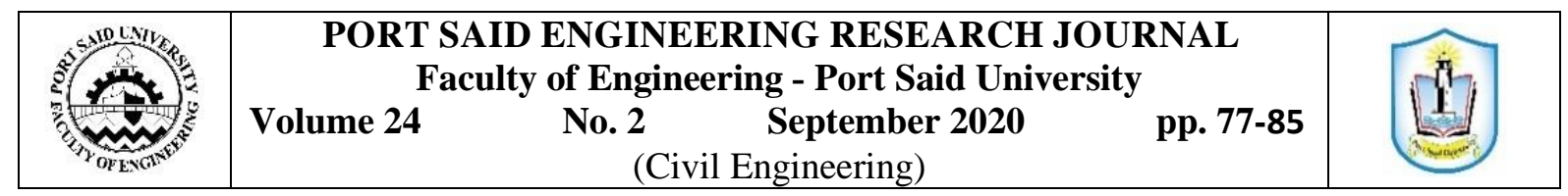

\title{
Detection of Seismic Movements Using GNSS Data
}

\author{
Rasha Mosad ${ }^{1}$, AshrafEl-kutb ${ }^{2}$, Ahmed El-Hattab ${ }^{3}$, Mostafa Rabah ${ }^{3}$ and, Ashraf El-Koshy ${ }^{5}$
}

Received: 14 July 2020; Accepted: 24 August 2020

\begin{abstract}
Nowadays, detecting the response level of ground shaking and studying its effect on the measurements of the surface motion are considered very important, because of the spread of natural disasters, such as earthquakes, volcanoes, and tsunamis. Such disasters lead to changes in the Earth's crust and hence movements of some points. Therefore, studying these movements has great benefits, such as the ability to predict the occurrence of an earthquake, which helps to control and minimize human and economic damages. It is possible to evaluate accurately the magnitude of point displacements and to find the factors affecting these displacements. In this research work, we explain the seismic monitoring techniques using the global navigation satellite system (GNSS), which considered a powerful tool for monitoring the ground points displacements, Bernese GNSS Software 5.2[4], was used to obtain high-precision of the results of the IGS stations data and their displacements, with the application on the network stations in the study area of Turkey,(Aegean sea earthquake).
\end{abstract}

KEYWORDS: Earthquake, point movement, GNSS, IGS data, Bernese5.2.

\section{INTRODUCTION}

Many earthquakes with moderate magnitude have occurred in many areas in the world The common procedures to extract the dynamic responses are mainly dependent on monitoring the change of the point or some other points in a time interval.[3]

Turkey is one of the countries has suffered from some of the worst earthquake, caused killing a lot of people and loss of much property. Turkey has a history of destructive seismic activity, and the recent days, the earthquakes are repeated each short time, so it is important to study the ground surface motion and the station's displacement as a result of shaking the earthquake.

The main objective of this paper is to study the effects of the Aegean sea,(Turkey) earthquake at 21/7/2017 in Turkey, and getting the station displacements on the earth's crust.depened on the time domain, that is mean we monitoring the response of earth in the three different days, on the day of the earthquake, a week before shaking and a week after shaking.

1 Civil Engineering Department, Faculty of Engineering, Port-said University, Egypt, corresponding author,

email:rashamosaad@gmail.com

2 Geodynamics Department, National Research Institute of Astronomy and Geophysics, Helwan, Cairo.email:Ashrafmousa07@gmail.com

3 Civil Engineering Department, Faculty of Engineering, Port-said University, port said, Egypt, email:dr.ahmed.elhattab@gmail.com

4 Civil Engineering Department, Faculty of Engineering, Banha University, Egypt, email: mostafa_rabah@eng.psu.edu.eg

5 Civil Engineering Department, Faculty of Engineering, Port-said University, Egypt, E-mail: dr.aelkoushy@gmail.com

DOI: $\underline{10.21608 / \text { pserj.2020.35662.1051 }}$
Global Navigation Satellite System has been proven to be an effective tool for monitoring the natural hazard as the earthquakes, by extracting the dynamic parameters accompanied by the earthquake, analyzing the seismic wave, and detecting the displacements of the points on the ground surface as a result of earthquake shaking.[9].

First step, getting data from the International GNSS Service ( IGS) which provides, the highest-quality GNSS data, Earth observation and research; positioning, navigation, timing products, and services in support of the terrestrial reference frame(ITRF).then the second step to processing these data by Bernese 5.2 GNSS processing software to obtain results within accuracy reach to millimeters.

The IGS stations [3], cover a closed network surrounding the epicenter of the Aegean earthquake (Kara Ada island), consisted of an inner network contains four stations: (ANKR-DYNG-MERS-NICO), which surrounded by an external network eight stations (ISTABUCU-BSHM-MAT1-ORDI-ISBA-ARUC).Figure(1).

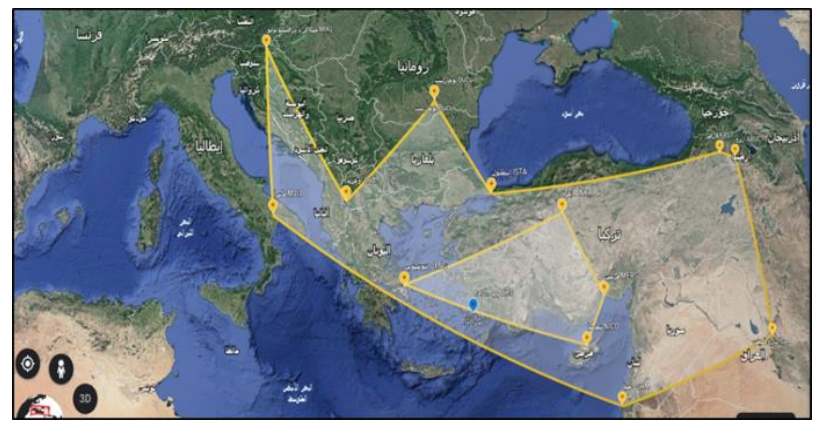

Figure 1: The earthquake stations network with epicenter KARA ADA. (Google Earth ). 


\section{GNSS SYSTEM FOR THE EARTHQUAKES}

Global Navigation Satellite Systems (GNSS) )[1], such as Global Positioning Systems (GPS) consist of several satellites orbiting high above the Earth in near-circular orbits Figure (2). A receiver can determine its location within a few minutes by measuring the time it takes a signal to travel to it from each satellite, utilizing the right equipment and accurate data processing; centimeter-level positioning can be achieved [2].

GNSS can be used to determine the magnitude of large earthquakes. This is achieved by measuring the displacement of the ground caused by the earthquake itself and monitoring stations close to the fault. For the largest earthquakes, such displacements can be huge: as large as several meters, and permanent displacements of a few millimeters can be identified thousands of kilometers away using GNSS. Figure(3).

The networks of GNSS monitoring stations can be used to estimate the amount of stress on a fault and hence be used to estimate seismic hazard, so GNSS can measure displacement in three dimensions, but only at specific points on the ground where the receivers are located.

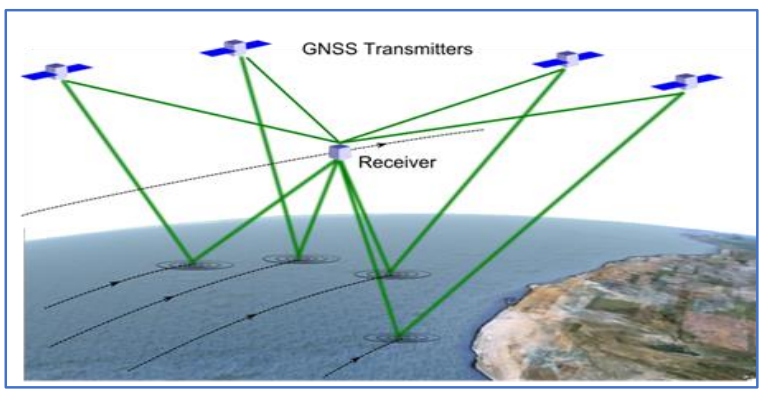

Figure 2: The GNSS system

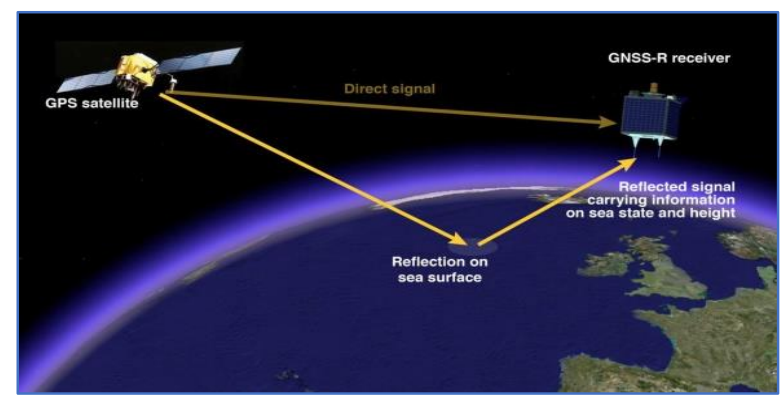

Figure 3: Get location by GNSS system

\section{THE AEGEAN EARTHQUAKE}

The 2017 Aegean Sea earthquake was a magnitude 6.7 on the Richter scale. with is considered very strong and caused a strong tsunami which had a maximum height of $1.9 \mathrm{~m}$. It occurred on 21 July 2017, about $10 \mathrm{~km}(6.2 \mathrm{mi})$ south-southeast of Bodrum, Turkey, at depth of about 10 km.[6].

The earthquake's epicenter was located just southwest of the small island of Kara Ada on the northern side of the Gulf of Gökova. The gulf is a result of extensional tectonics related to the ongoing subduction of the African Plate beneath the Aegean Sea Plate.Figure(4)

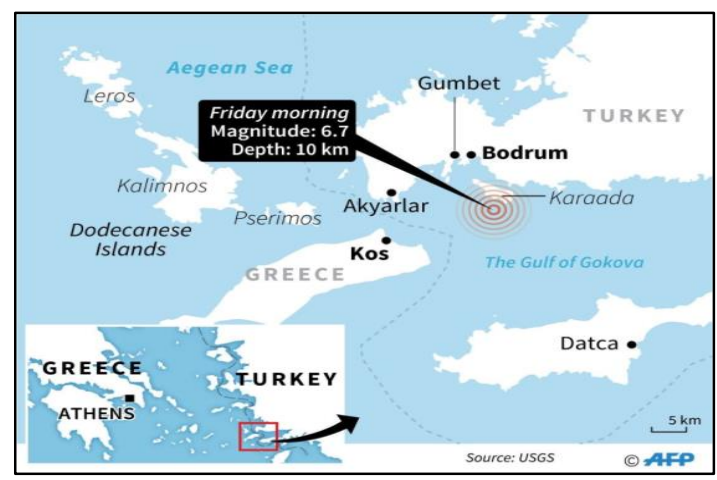

Figure 4: Map of KARAADA island, the epicenter of the earthquake.

\section{METHODOLOGY OF GETTING POINTS POSITIONS USING GNSS DATA}

The proposed methodology is to make a network of IGS stations surrounding the Aegean earthquake epicenter, the baselines linked to each other deployed within the borders of Turkey and abroad, table(1), then monitor shaking effects of these stations and the Earth's crust movements in all directions $\mathrm{X}, \mathrm{Y}, \mathrm{Z}$, and obtain all possible information can help us to make a tool of early prediction of earthquakes and reduce many of the risks and victims. The time-domain starts with the day of the Aegean earthquake that occurred at $21 / 7 / 2017$, then one week before the earthquake at $14 / 7 / 2017$, and finally on the day of one week after the earthquake at 28/7/2017.

After getting all the required data from IGS service, the second step, making the processing of all data in each monitoring time separately, by using Bernese 5.2 GNSS software. [8].

The following flow chart, Figure (5), explains all steps from collecting data to process data with two main operations first, the pre-processing stage, and the processing stage.

The output after Bernese processing appears in the ADDNEQ file, which contains the solution of each selected station of our network, such as the estimated station's coordinates and velocities, RMS error, and several observations and parameters for 24 hours to each point. And all steps of the previous operation repeated for the other two campaigns with different day. Figure (5)

Tabel 1: The chosen Network Baselines Stations

\begin{tabular}{|c|c|}
\hline station1 & station2 \\
\hline DYNG & NICO \\
DYNG & MERS \\
MERS & NICO \\
NICO & ANKR \\
DYNG & ANKR \\
DYNG & ISTA \\
DYNG & ORID \\
DYNG & MIKL \\
MAT1 & DYNG \\
MAT1 & MIKL \\
NICO & ISBA \\
BSHM & NICO \\
ANKR & ARUC \\
ISBA & ARUC \\
DYNG & BSHM \\
\hline
\end{tabular}




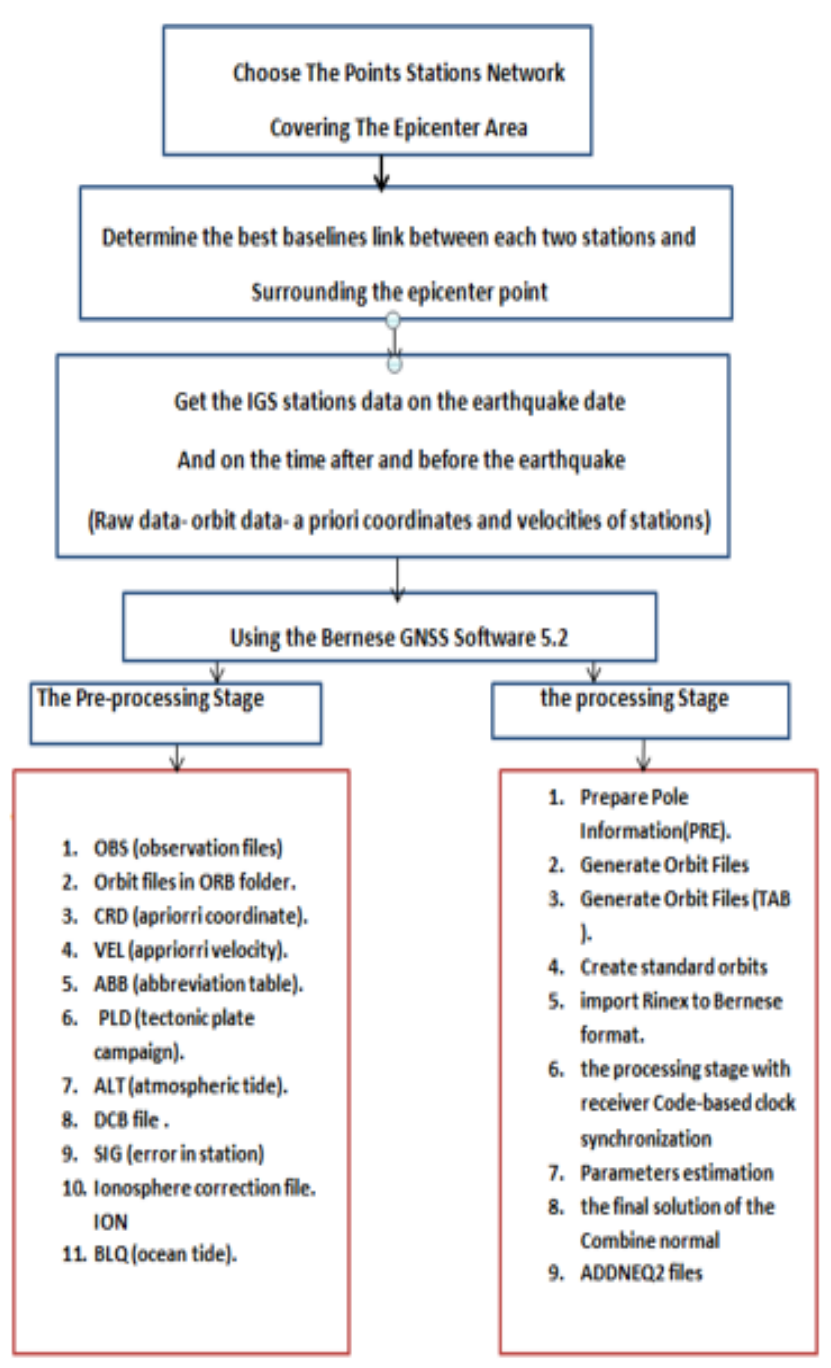

Figure 5: Flow Chart of work methodology

\subsection{The Data of three different days of the Aegean Earthquake}

After getting the final result file (ADDNEQ file) from Bernese GNSS software version 5.2, we get all the estimated coordinates X, Y and Z for date 14/7/2017 of Aegean earthquake, and computed $\mathrm{dX}=\mathrm{X} 1-\mathrm{X} 2$, which $\mathrm{X} 1$, $\mathrm{X} 2$ the coordinates of station 1 and station 2 for the baseline number 1 , Similarly, we computed $\mathrm{dY}=\mathrm{Y} 1-\mathrm{Y} 2$ and $\mathrm{dZ}=\mathrm{Z1}-\mathrm{Z} 2$. Tabel (2).

Table 2: Baselines Data before the earthquake

\begin{tabular}{|c|c|c|c|c|}
\hline \multicolumn{2}{|c|}{ Aegean Sea-Earthqauke-Turky } & \multicolumn{2}{c|}{ the day before 14-7 } \\
\hline station1 & station2 & X1 & X2 & dX2 (m) \\
\hline DYNG & NICO & 4595220.08403 & 4359415.53318 & 235804.55085 \\
DYNG & MERS & 4595220.08403 & no data & no data \\
MERS & NICO & no data & 4359415.53318 & no data \\
\hline NICO & ANKR & 4359415.53318 & 4121948.46664 & 237467.06654 \\
DYNG & ANKR & 4595220.08403 & 4121948.466664 & 473271.61739 \\
DYNG & ISTA & 4595220.08403 & 4208830.11909 & 386389.96494 \\
DYNG & ORID & 4595220.08403 & 4498451.54271 & 96768.54132 \\
DYNG & MIKL & 4595220.08403 & 3698553.77461 & 896666.30942 \\
MAT1 & DYNG & 4641951.25943 & 4595220.08403 & 46731.17540 \\
MAT1 & MIKL & 4641951.25943 & 3698553.77461 & 943397.48482 \\
NICO & ISBA & 4359415.53318 & 3808364.65438 & 551050.87880 \\
BSHM & NICO & 4395951.24856 & 4359415.53318 & 36535.71538 \\
ANKR & ARUC & 4121948.46664 & 3500416.72025 & 621531.74639 \\
ISBA & ARUC & 3808364.65438 & 3500416.72025 & 307947.93413 \\
DYNG & BSHM & 4595220.08403 & 4395951.24856 & 199268.83547 \\
\hline
\end{tabular}

It is Noticeable that there is no available data for MERS station for day 14/7/2017 because there was no raw data on this date at the IGS site, it was maybe due to the maintenance work of the station or change of the receiver which makes the station to stop working.

Likewise, the rest of the data was calculated in the two other dates. Tables $(3,4)$.

Table 3: Table of Baselines Data on the day of the earthquake

\begin{tabular}{|c|c|c|}
\hline & & Day 21-7-2017 \\
\hline 451 & $\mathrm{X} 2$ & $\mathrm{dX} 1(\mathrm{~m})$ \\
\hline 4595219.96307 & 4359415.40638 & 235804.55669 \\
\hline 4239149.20328 & 4239149.20328 & 356070.75979 \\
\hline 4359415.40638 & 4359415.40638 & 120266.20310 \\
\hline 4595219.96307 & 4121948.34884 & 237467.05754 \\
\hline 4595219.96307 & 4121948.34884 & 473271.61423 \\
\hline 4595219.96307 & 4208829.99693 & 386389.96614 \\
\hline 4595219.96307 & 4498451.42195 & 96768.54112 \\
\hline 4641951.14757 & 3698553.65981 & 896666.30326 \\
\hline 4641951.14757 & 4595219.96307 & 46731.18450 \\
\hline 4359415.40638 & 3698553.65981 & 943397.48776 \\
\hline 4395951.13511 & 3808364.53802 & 551050.86836 \\
\hline 4121948.34884 & 4359415.40638 & 36535.72873 \\
\hline 3808364.53802 & 3500416.60685 & 621531.74199 \\
\hline 4595219.96307 & 3500416.60685 & 307947.93117 \\
\hline
\end{tabular}

Table 4: Baselines Data after the earthquake

\begin{tabular}{|c|c|c|}
\hline & & After 28-7-2017 \\
\cline { 3 - 3 }$X 1$ & $X 2$ & $d X 3(\mathrm{~m})$ \\
\hline 4595220.01173 & 4359415.46265 & 235804.54908 \\
\hline 4595220.01173 & 4239149.26264 & 356070.74909 \\
\hline 4239149.26264 & 4359415.46265 & 120266.20001 \\
\hline 4359415.46265 & 4121948.39849 & 237467.06416 \\
\hline 4595220.01173 & 4121948.39849 & 473271.61324 \\
\hline 4595220.01173 & 4208830.05050 & 386389.96123 \\
\hline 4595220.01173 & 4498451.50160 & 96768.51013 \\
\hline 4595220.01173 & 3698553.70386 & 896666.30787 \\
\hline 4641951.20065 & 4595220.01173 & 46731.18892 \\
\hline 4641951.20065 & 3698553.70386 & 943397.49679 \\
\hline 4359415.46265 & 3808364.58276 & 551050.87989 \\
\hline 4395951.18193 & 4359415.46265 & 36535.71928 \\
\hline 4121948.39849 & 3500416.65806 & 621531.74043 \\
\hline 3808364.58276 & 3500416.65806 & 307947.92470 \\
\hline 4595220.01173 & 4395951.18193 & 199268.82980 \\
\hline
\end{tabular}

Like these data in the tables, we computed $\mathrm{dY}$ and $\mathrm{dZ}$ in the three different days of an Aegean earthquake. Take the first baseline (DYNG-NICO) is an example to compare between results of $\mathrm{dX}, \mathrm{dY}$, and $\mathrm{dZ}$ in meter on the three different days as a bar chart. Fig $(6,7,8)$.

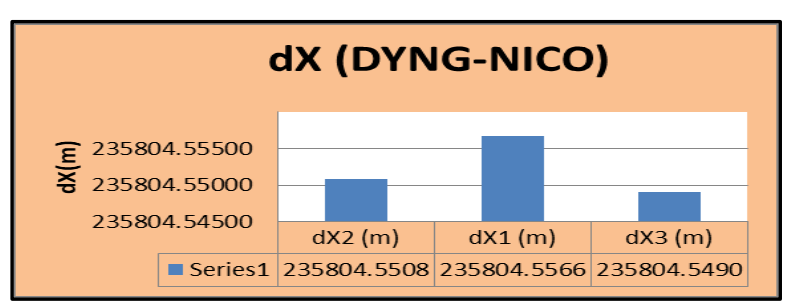

Figure 6: dX bar chart of the baseline

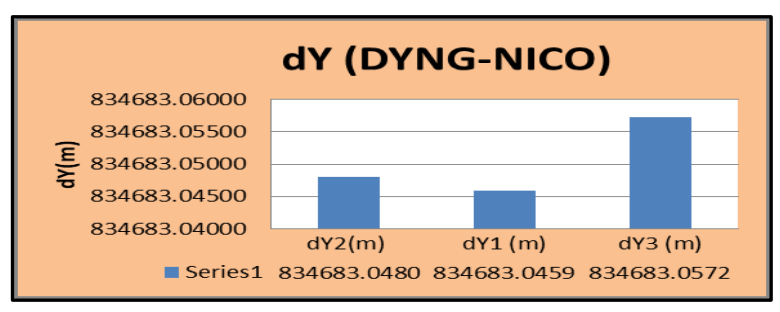

Figure 7: dY bar chart of the same baseline 


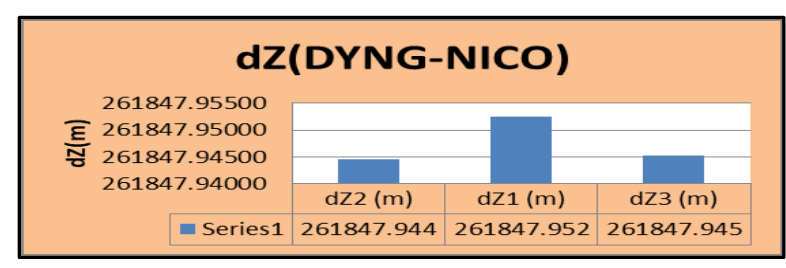

Figure 8: Diagram of $d Z$ bar chart of the same baseline

The values of $d X 2, d Y 2$, and dZ2are represent the data a week before the earthquake at 14/7/2017, while the $\mathrm{dX} 1, \mathrm{dY} 1$ and $\mathrm{dZ1}$ on the day of the earthquake at $21 / 7 / 2017$, and $d X 3,3$ and $d Z 3$ are the data of one week after the earthquake at 28/7/2017.

From the previous bar charts, we noticed that that $\mathrm{dX} 2$ is lower than $\mathrm{dX} 1$. dX1 increases, and then decreases to reach value $\mathrm{dX} 3$ which seems to go to the normal statue after an earthquake finished. Figure(6).

Figure(7) shows that $\mathrm{dY}$ increased at the day before the earthquake then decreased by small value on $d Y 1$, then increased again after the earthquake is over. Maybe this happened when the earthquake forces were still affecting the earth surface due to the nature of the earth in this region or maybe another earthquake will occur soon.

In figure (8), it is noticed that $\mathrm{dZ}$ increased on the day of the earthquake than before it, and then decreased again as begin. But we found that the magnitude of values increased from $1 \mathrm{~mm}$ to $1 \mathrm{~cm}$ in the three coordinates of point stations, it may be because of the nature of the ground in these stations regions.

\subsection{Compute The Values of The Baselines Length's displacements}

It is very important to compute the baseline displacement value between all the network points stations $\Delta \mathrm{dx}, \Delta \mathrm{dy}, \Delta \mathrm{dz}$, to tell us the amount of expansion or contraction values happened on these baselines, so it can be a monitoring tool of the movement of the point on the surface of the earth's crust.Table(5)

Tabel 5: Shows all $\Delta d x, \Delta d Y$, and $\Delta d Z$ of the all baselines network in meter.

\begin{tabular}{|c|c|c|c|c|c|c|}
\hline Baselines & dodim & $\Delta 00 \times 3 \mathrm{~m}$ & Dol1 m & $\Delta \mathrm{N} / 3 \mathrm{~m}$ & dolim & $\triangle d B m$ \\
\hline baselinel & .00584 & 00017 & 0.0214 & .00019 & .20001 & -00074 \\
\hline baseline2 & nodata & nodtata & nodita & nodita & nodata & nodath \\
\hline baseline3 & nodda & nodta & noddata & nodita & nodota & nodata \\
\hline baselinet & 0.00900 & 000238 & 0.0658 & 0.00000 & .001550 & -000745 \\
\hline baselinef & 0.00316 & 0.00415 & 1.0049 & .000079 & .000759 & .00061 \\
\hline baseline6 & .00120 & 0.00331 & 0.00102 & .000119 & .00458 & -000330 \\
\hline baseline? & 0.00000 & 003119 & 1.00078 & 0.01531 & .00043 & -009176 \\
\hline baselines & 0.00616 & D00155 & 0.0552 & .00145 & .001573 & .001701 \\
\hline baselineg & .00910 & 001352 & 0.00118 & 0.00551 & .003319 & .00519 \\
\hline baseline10 & .000284 & 0.01197 & . .00710 & .000054 & .001254 & -001182 \\
\hline baseline11 & 0.0104 & .00109 & 0.01216 & .00512 & 0.01225 & 0.00735 \\
\hline baseline12 & .001355 & .00330 & 0.01106 & .000210 & 0.01521 & 0.0075 \\
\hline baseline13 & 0.0040 & 0.00596 & 4.0002 & .001114 & .000318 & .001123 \\
\hline baseline14 & 0.00280 & 000043 & 0.00359 & 0.0062 & .000583 & -0011133 \\
\hline baseline15 & 0.00751 & 000557 & 0.08812 & .001129 & 0.0076 & $0.0 \% 1$ \\
\hline
\end{tabular}

In table (5), shows the values of the network baselines displacements of $\Delta \mathrm{dX}, \Delta \mathrm{dY}$, and $\Delta \mathrm{dZ}$, taking into consideration that: $\Delta \mathrm{dx} 1=\Delta \mathrm{d} \times 2-\Delta \mathrm{dx} 1(\mathrm{~m})$, and $\Delta \mathrm{d} \times 3=$ $\Delta \mathrm{dx} 2-\Delta \mathrm{dx} 3(\mathrm{~m})$, This mean that we took $\Delta \mathrm{dx} 2$ as a reference value of our calculations, likewise, $\Delta \mathrm{dY} 2$ and $\Delta \mathrm{dZ2}$ was taken as a reference of the equations to get values of $\Delta \mathrm{dY} 1, \Delta \mathrm{dY} 3, \Delta \mathrm{dZ} 1$ and $\Delta \mathrm{dZ} 3$.

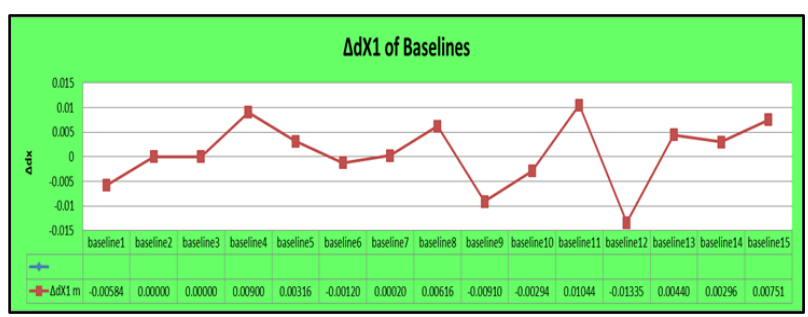

\section{Figure 9:The diagram of $\Delta \mathrm{dX} 1$ on the day of the Earthquake}

From the diagram, Figure(9). we noticed that the length of the first baseline (DYNG-NICO) increased by $5 \mathrm{~mm}$ which $\Delta \mathrm{dX} 1=-0.005 \mathrm{~m} \quad(5 \mathrm{~mm})$, which $\Delta \mathrm{dX} 1=(\mathrm{dX} 2-\mathrm{dX} 1)$ $\mathrm{m}$ and this is referred to the effect of the earthquake on these two stations which is considered one of the nearest stations from the epicenter of the earthquake. The two baselines number 2 and 3 (DYNG-MERS) and (MERSNICO) we could not draw their changes, because there was no raw data of MERS station on 14/7/2017. the baseline number 4 (NICO-ANKR) decreases its length by $9 \mathrm{~mm}$ where $\Delta \mathrm{dX} 1=+0.009 \mathrm{~m}$. we noticed that the earthquake shaking affected these two stations because of their closeness from the earthquake center. The baseline number 5 (DYNG-ANKR) also decreased its length by 3 $\mathrm{mm}$ on the day of one week before the earthquake, this could be an indication of the accumulation of the forces of this earthquake to occur on its close time. With such a study, the prediction of earthquakes will be easier, keeping the daily monitoring of earth crust movements help us to have an early warning system.

The baseline number 6 (DYNG-ISTA) has $\Delta \mathrm{dX} 1=$ $0.001 \mathrm{~m}$, that shows the increase in the length of baseline on the day of the earthquake from the day before it by $1 \mathrm{~mm}$. The length of baselines number 8 reduced about $6 \mathrm{~mm}$, and baselines 9and 10 have increased their lengths of $2 \mathrm{mmto} 9 \mathrm{~mm}$, but we noticed that baseline 11 has a contraction of $1 \mathrm{~cm}$ and number 12 have an expansion of $1 \mathrm{~cm}$ as the two stations near from the epicenter of the earthquake, and the final baselines 13,14 and 15 all have length reduction about $2 \mathrm{~mm}$ to $7 \mathrm{~mm}$.

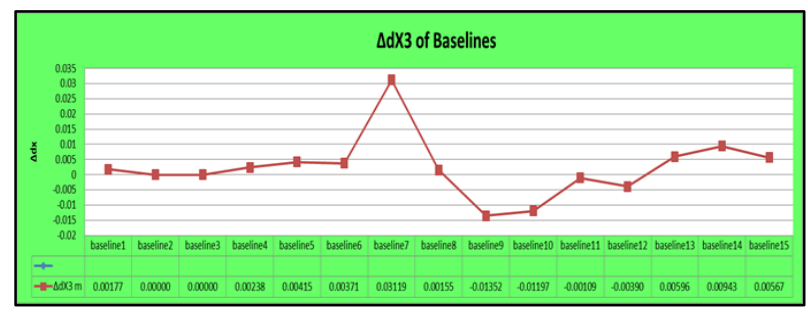

Figure 10: The Diagram of $\Delta \mathrm{dX} 3$ a week after the earthquake

This graph, Figure (10), illustrates the changes of values $\mathrm{dx}$ after a week of the earthquake shaking, the first baseline decreased, which $\Delta \mathrm{dx} 3=+.0 .00177 \mathrm{~m}$, about $2 \mathrm{~mm}$ that means The Earth's crust returns gradually to its 
normal case. There is no change in baselines numbers 2 and 3 as no available data for MERS station. The baselines 4,5 and 6 the $\Delta \mathrm{dx}$ with a positive signal that means the lengths were less than its previous value before the earthquake of about 2 to $4 \mathrm{~mm}$. This means the Earth's crust begins to be relatively stable again. Even though we noticed that the baseline number 7 (DYNG-ORID) changed very clearly, up to $3 \mathrm{~cm}$, the reason for that high displacement value probably as a result of the proximity of the two stations to the epicenter of the earthquake or because of the mountain topography of Macedonia, which included the ORID station and exposed consecutively with earthquakes. Like these displacements, it may be indicated that an earthquake will be coming soon or the aftershocks sequence. The other baselines displacements have values ranging from $1 \mathrm{~mm}$ and $5 \mathrm{~mm}$ except baseline numbers 9 and 10 equal $1 \mathrm{~cm}$.

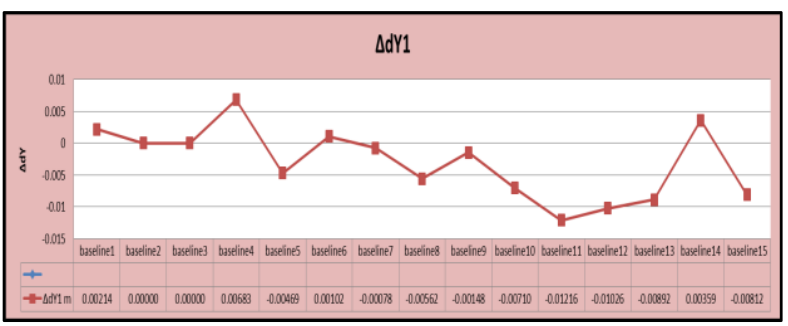

Figure 11: The Diagram of $\Delta d Y 1$ on the day of the earthquake

The graph in figure (11), shows that the baselines numbers $1,4,6$, and 14 were subjected to a decrease in their lengths between each two stations in a range of $1 \mathrm{~mm}$ to $4 \mathrm{~mm}$.

On the other hand, the rest of the baselines were exposed to an increase in the length between each of them in a range of $1 \mathrm{~mm}$ to $1 \mathrm{~cm}$ as a maximum value.

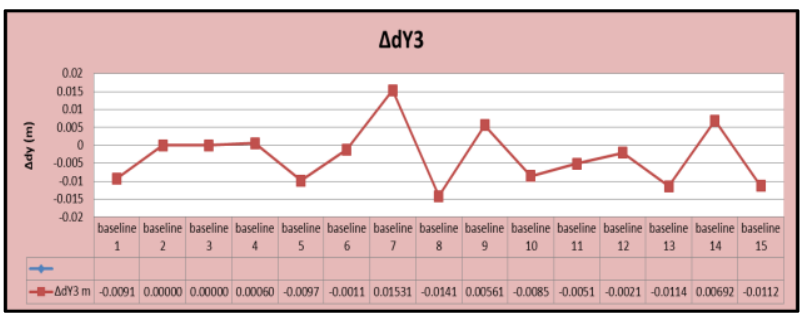

Figure 12: The Diagram of $\Delta d Y 3$ a week after the earthquake

the graph in figure (12), explains that the changes in $\Delta d$ Yof baselines number $7,8,10,13$ and 15 reached to values $1 \mathrm{~cm}$ to $1.5 \mathrm{~cm}$. because some of their stations are near the epicenter like (DYNG, ANKR, ISTA), but we noticed also that the far stations (MIKL, ORID, NICO, ARUC, and BSHM), linked between the same baselines $7,8,10,13,15$. So, this displacement value may be a result of the nature of the rocky ground and the frequency rate of natural disasters in these areas. I.e.it makes the storage of earthquakes forces inside the earth not finished yet and the surface stability will be delayed.

In Figure (13) we noticed that values range in most of baselines from $3 \mathrm{~mm}$ to $8 \mathrm{~mm}$ at stations NICO, DYNG, ISTA which considered closer to the earthquake center.it may be a sign of station movements before earthquake shaking as a result of gathering the forces of an earthquake underground surface and then an earthquake will occur after a certain time. The Baselines numbers 10,11 and 12 have values of $1 \mathrm{~cm}$, it may be dependent on the soil nature of their regions which helped to make bigger movements of their points.

In Figure (14), most points have small displacements ranged between $6 \mathrm{~mm}$ and $7 \mathrm{~mm}$, so it was easy to reach to their stability case. For some other stations, the values of $\Delta \mathrm{dZ3}$ were very big, like stations of ORID the value equal $9 \mathrm{~cm}$, which may indicate another earthquake in its area will happen soon.

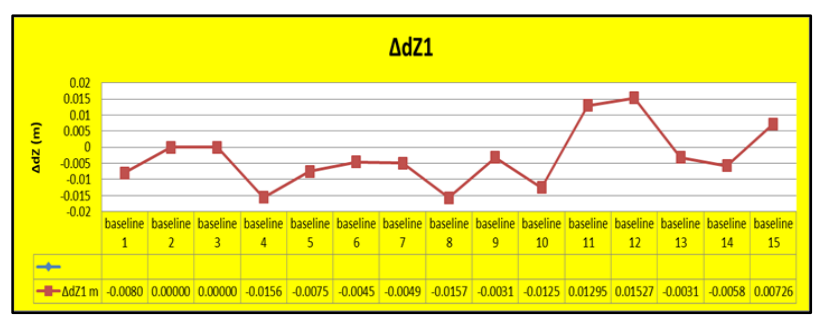

Figure 13: The Diagram of $\Delta d Z 1$ on the day of the earthquake

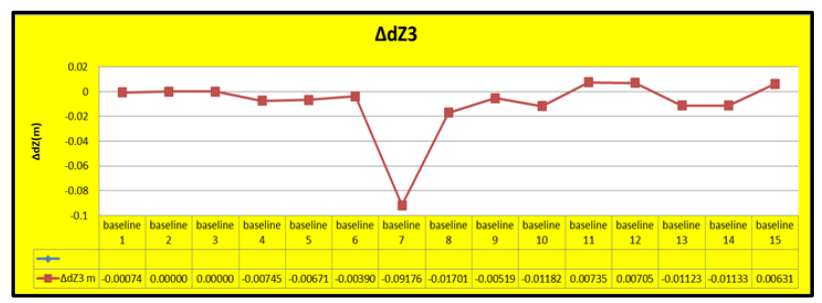

Figure 14: The Diagram of $\Delta d Z 3$ on a week after the earthquake

\section{THE HEIGHTS DISPLACEMENT OF THE BASELINES POINTS}

From the output file of Bernese GNSS processing, we extracted also the heights values of each station of our Aegean network, and calculated the height difference between every two stations of the baselines. the following tables explain the values of stations heights difference in the three different dates from the earthquake. Tables $(6,7,8)$.

Table 6: The station's height difference values on a week before the earthquake

\begin{tabular}{|c|c|c|c|c|}
\hline \multicolumn{5}{|l|}{$14 / 7 / 2017$} \\
\hline station1 & station2 & $\mathrm{h} 1(\mathrm{~m})$ & $\mathrm{h} 2(\mathrm{~m})$ & dh2 week before anearthquke \\
\hline DYNG & NICO & 510.60444 & 190.05154 & 320.55290 \\
\hline DYNG & MERS & 510.60444 & no data & no data \\
\hline MERS & NICO & no data & 190.05154 & no data \\
\hline NICO & ANKR & 976.03127 & 190.05154 & 785.97973 \\
\hline DYNG & ANKR & 976.03127 & 510.60444 & 465.42683 \\
\hline DYNG & ISTA & 510.60444 & 147.27504 & 363.32940 \\
\hline DYNG & ORID & 773.04057 & 510.60444 & 262.43613 \\
\hline DYNG & MIKL & 510.60444 & 93.93712 & 416.66732 \\
\hline MAT1 & DYNG & 534.55785 & 510.60444 & 23.95341 \\
\hline MAT1 & MIKL & 534.55785 & 93.93712 & 440.62073 \\
\hline NICO & ISBA & 190.05154 & 72.38347 & 117.66807 \\
\hline BSHM & NICO & 225.08876 & 190.05154 & 35.03722 \\
\hline ANKR & ARUC & 1222.16714 & 976.03127 & 246.13587 \\
\hline ISBA & ARUC & 1222.16714 & 72.38347 & 1149.78367 \\
\hline DYNG & BSHM & 510.60444 & 225.08876 & 285.51568 \\
\hline
\end{tabular}


Table 7: The station's heights difference values on the day of the earthquake

\begin{tabular}{|c|c|c|c|c|}
\hline \multicolumn{5}{|c|}{$21 / 7 / 2017$} \\
\hline station1 & station2 & $h 1(m)$ & $\mathrm{h} 2(\mathrm{~m})$ & dh1 the day of earthquke \\
\hline DYNG & NICO & 510.48986 & 189.92874 & 320.56112 \\
\hline DYNG & MERS & 510.48986 & 38.48829 & 472.00157 \\
\hline MERS & NICO & 189.92874 & 38.3816 & 151.54714 \\
\hline NICO & ANKR & 975.93072 & 189.92874 & 786.00198 \\
\hline DYNG & ANKR & 975.93072 & 510.48986 & 465.44086 \\
\hline DYNG & ISTA & 510.48986 & 147.16701 & 363.32285 \\
\hline DYNG & ORID & 772.93157 & 510.48986 & 262.44171 \\
\hline DYNG & MIKL & 510.48986 & 93.85211 & 416.63775 \\
\hline MAT1 & DYNG & 534.4531 & 510.48986 & 23.96324 \\
\hline МАТ1 & MIKL & 534.54922 & 93.85211 & 440.69711 \\
\hline NICO & ISBA & 189.92874 & 72.28833 & 117.64041 \\
\hline BSHM & NICO & 224.98775 & 189.92874 & 35.05901 \\
\hline ANKR & ARUC & 1222.08394 & 975.93072 & 246.15322 \\
\hline ISBA & ARUC & 1222.08394 & 72.28833 & 1149.79561 \\
\hline DYNG & BSHM & 510.48986 & 224.98775 & 285.50211 \\
\hline
\end{tabular}

Table 8: The station's heights difference values on a week after the earthquake

\begin{tabular}{|c|c|c|c|c|}
\hline \multicolumn{5}{|l|}{$28 / 7 / 2017$} \\
\hline station 1 & station2 & $\mathrm{h} 1(\mathrm{~m})$ & $\mathrm{h} 2(\mathrm{~m})$ & dh3 week after of earthquke \\
\hline DYNG & NICO & 510.49534 & 189.95338 & 320.54196 \\
\hline DYNG & MERS & 510.49534 & 38.40763 & 472.08771 \\
\hline MERS & NICO & 189.95338 & 38.40763 & 151.54575 \\
\hline NICO & ANKR & 975.93607 & 189.95338 & 785.98269 \\
\hline DYNG & ANKR & 975.93607 & 510.49534 & 465.44073 \\
\hline DYNG & ISTA & 510.49534 & 147.17193 & 363.32341 \\
\hline DYNG & ORID & 773.01540 & 510.49534 & 262.52006 \\
\hline DYNG & MIKL & 510.49534 & 93.84612 & 416.64922 \\
\hline MAT1 & DYNG & 534.45982 & 510.49534 & 23.96448 \\
\hline MAT1 & MIKL & 534.45982 & 93.84612 & 440.61370 \\
\hline NICO & ISBA & 189.95338 & 72.30099 & 117.65239 \\
\hline BSHM & NICO & 225.00105 & 189.95338 & 35.04767 \\
\hline ANKR & ARUC & 1222.09551 & 975.93607 & 246.15944 \\
\hline ISBA & ARUC & 1222.09551 & 72.30099 & 1149.79452 \\
\hline DYNG & BSHM & 510.49534 & 225.00105 & 285.49429 \\
\hline
\end{tabular}

To evaluate the changes happened on the height displacements we calculated the values of $\Delta \mathrm{dh} 1$ and $\Delta \mathrm{dh} 3$, Where, as with $\mathrm{X}, \mathrm{Y}$ and $\mathrm{Z}, \Delta \mathrm{dh} 1=\mathrm{dh} 2-\mathrm{dh} 1$ in meter, and $\Delta \mathrm{dh} 3=\mathrm{dh} 2-\mathrm{dh} 3$ in meter. The dh2 values are taken as a reference to calculate both of $\Delta \mathrm{dh} 1$ and $\Delta \mathrm{dh} 3$.

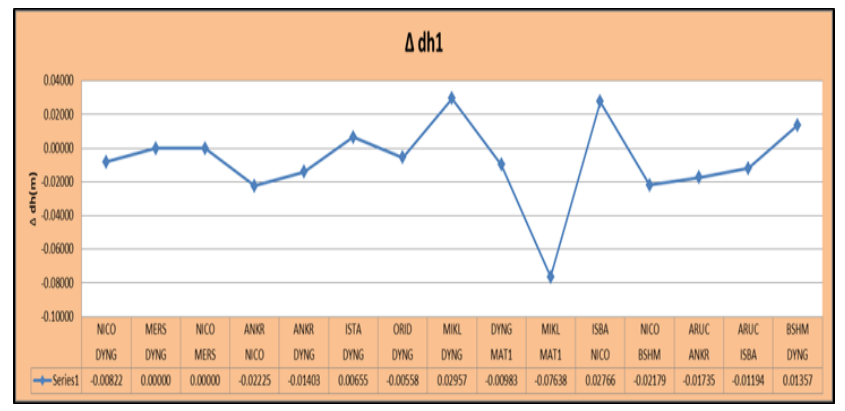

Figure 15: The graph of $\Delta \mathrm{dh} 1$ on the day of an earthquake

The graph in figure (15), shows the magnitude of changes in the height displacement of the stations on the day of an earthquake, the first baseline increased about $8 \mathrm{~mm}$. the next two baselines have no data available because of MERS station has no raw data on this date, then the baselines number 4,5 height increased $2 \mathrm{~cm}$ and $1 \mathrm{~cm}$. Similarly, most values increased or decreased in the range of $5 \mathrm{~mm}$ to $2 \mathrm{~cm}$. But the baseline (MIKl-MAT1) has a more increased value of $7 \mathrm{~cm}$, that means the baseline greatly affected the earthquake because of their statins locations and topography.

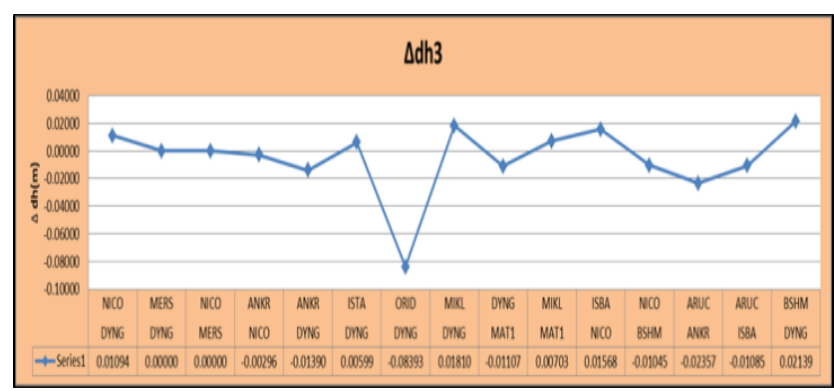

Figure 16: The graph of $\Delta \mathrm{dh} 3$ a week after the earthquake

From this graph 16, we notice that the height of the first baseline decreased about $1 \mathrm{~cm}$ after its increase on the day of the earthquake. In the next two baselines, the heights displacements increased by $2 \mathrm{~mm}$ and $1 \mathrm{~cm}$, which means that some stations return to its stability gradually from the day of the earthquake until a week after it.

But the big height displacement happened on the baseline of (ORDI-DYNG) which has an increased value of $8 \mathrm{~cm}$. Although it has a slight value on the day of earthquake equal $5 \mathrm{~mm}$, it may be a sign of another earthquake near this area or these stations.

The baseline (MIKL-DYNG) has about a $2 \mathrm{~cm}$ decreased value, but on the day of an earthquake, it has a displacement value of about $3 \mathrm{~cm}$. we notice that the biggest displacement value of the baseline (MIKLMAT1) on the day of the earthquake was $7 \mathrm{~cm}$ increased value. But it changed after one week to reach a value of 7 $\mathrm{mm}$ as a decrease value, that change makes us believe that the station returned to its normal case after finishing the effect of earthquake forces.

\section{THE AFTERSHOCK AEGEAN EARTHQUAKE DISPLACEMENTS}

To make the study of the movement of points of the Earth's crust an important tool for predicting the earthquakes, it is necessary to periodically monitor these stations at consecutive and regular periods to achieve the greatest accuracy of the results and help us in the future.

So the Aegean aftershocks were monitored three months later at 27/10/2017, first we used the Bernese GNSS software 5.2 to processing the raw data of our stations in the same network get finally the estimated coordinates of all points according to the free network solution. then we get all data we needed in the three different days of aftershock the day of earthquake 27/10/2017, a week before the earthquake 20/10/2017, and after two weeks from shocking on 10/11/2017, because there was not any available raw data on the date of a week after an earthquake. The same previous scenario will be repeated in the calculation of aftershock displacements. 
Table 9: $\mathrm{dX}$ for the network baselines on day of

\begin{tabular}{|c|c|c|c|c|}
\hline & \multicolumn{4}{c|}{ the day of earthqauke 27-10-2017 } \\
\hline STATIONS1 & STATIONS2 & $\mathrm{X} 1(\mathrm{~m})$ & $\mathrm{X} 2(\mathrm{~m})$ & $\mathrm{dX1}(\mathrm{m})$ \\
\hline NICO & DYNG & 4359415.50618 & 4595220.05789 & 235804.55171 \\
DYNG & MERS & 4595220.05789 & 4239149.30559 & 356070.75230 \\
MERS & NICO & 4239149.30559 & 4359415.50618 & 120266.20059 \\
\hline NICO & ANKR & 4359415.50618 & 4121948.44327 & 237467.06291 \\
\hline DYNG & ANKR & 4595220.05789 & 4121948.44327 & 473271.61462 \\
DYNG & ISTA & 4595220.05789 & 4208830.09197 & 386389.96592 \\
DYNG & ORID & 4595220.05789 & 4498451.52004 & 96768.53785 \\
DYNG & MIKL & 4595220.05789 & 3698553.75646 & 896666.30143 \\
MAT1 & DYNG & 4641951.23944 & 4595220.05789 & 46731.18155 \\
MAT1 & MIKL & 4641951.23944 & 3698553.75646 & 943397.48298 \\
\hline NICO & ISBA & 4359415.50618 & 3808364.63131 & 551050.87487 \\
BSHM & NICO & 4395951.22298 & 4359415.50618 & 36535.71680 \\
ANKR & ARUC & 4121948.44327 & 3500416.70471 & 621531.73856 \\
ISBA & ARUC & 3808364.63131 & 3500416.70471 & 307947.92660 \\
DYNG & BSHM & 4595220.05789 & 4395951.22298 & 199268.83491 \\
\hline
\end{tabular}

Table 10: $d Y$ and $d Z$ for the network baselines

\begin{tabular}{|c|c|c|c|c|c|}
\hline$\gamma_{1}(\mathrm{~m})$ & $\mathrm{r} 2(\mathrm{~m})$ & $d Y 1(m)$ & $21 . \mathrm{m})$ & $22(\mathrm{~m})$ & $\mathrm{d} z 1(\mathrm{~m})$ \\
\hline 2874117.21017 & 20394344.16125 & 834683.04892 & 3650777.99348 & 3912625.93267 & 261847.93919 \\
\hline 2039434.16125 & 2886968.01203 & 847533.85078 & 3912625.93267 & 3778877.15882 & 133748.77385 \\
\hline 2886968.01203 & 2874117.21017 & 12850.80186 & 3778877.15882 & 3650777.993 & 128099.16534 \\
\hline 2874117.21017 & 2652187.86010 & 221929.35007 & 365077.993 & 4069023.85355 & 418245.86007 \\
\hline 2039434.16125 & 2652187.86010 & 612753.69885 & 3912625.93267 & 4069023.85355 & 156397.92088 \\
\hline 2039434.16125 & 2334850.52755 & 295416.36630 & 3912625.93267 & 4171267.36788 & 258641.43521 \\
\hline 2039434.16125 & 1708267.23569 & 331166.92556 & 3912625.93267 & 4173591.985 & 260966.05196 \\
\hline 2039434.16125 & 2308676.21135 & 269242.05010 & 3912625.93267 & 4639769.615 & 727143.68219 \\
\hline 1393053.90251 & 2039434.16125 & 646380.25874 & 4133281.059 & 3912625.93267 & 200655.12592 \\
\hline 1393053.90251 & 2308676.21135 & 915622.30884 & 4133281.059 & 4639769.615 & 506488.55627 \\
\hline 2874117.21017 & 3734430.20182 & 860312.99165 & 3650777.993 & 3485693.68 & 165084.31343 \\
\hline 3080707.21539 & 2874117.21017 & 206590.00522 & 3433498.25 & 3650777.993 & 217279.74372 \\
\hline 2652187.86010 & 3390432.73954 & 738244.87944 & 4069023.85355 & 4103027.64111 & 34003.78756 \\
\hline 3734430.20182 & 3390432.73954 & 343997.46228 & 3485693.68 & 4103027.64111 & 617333.96106 \\
\hline 20394434,16125 & 3080707.21539 & 10412733.05414 & 39912625.93267 & 34334998.25 & 479127.68291 \\
\hline
\end{tabular}

The same table for $\mathrm{dX}, \mathrm{dY}$, and $\mathrm{dZ}$ for the other two different times of the earthquake have been calculated also. then we calculated the values of the baselines displacements to know the movement of both of the joint stations in the baseline in the three chosen times, determine whether there has been an expansion or contraction of its original length due to the impact of the earthquake.Tables $(9,10,11,12,13)$.

Table 11: $\Delta \mathrm{dX} 1$ and $\Delta \mathrm{dX} 3$ of the network baselines

\begin{tabular}{|c|c|c|c|c|c|c|}
\hline station1 & station2 & $d \times 2(m)$ & $d x 1(m)$ & $d x 3(m)$ & $\Delta d X 1=(d X 2-d x 1) / m$ & $\Delta d X 3=(d \times 2-d x 3) \mathrm{m}$ \\
\hline NICO & DYNG & 235804.55385 & 235804.55171 & 235804.55784 & 0.00214 & $\cdot 0.00399$ \\
\hline DYNG & MERS & 356070.75204 & 356070.75230 & 356070.75848 & $\cdot 0.00026$ & $\cdot 0.00644$ \\
\hline MERS & NICO & 1202666.19819 & 120266.20059 & 120266.20064 & $\cdot 0.00240$ & 0.00245 \\
\hline NICO & ANKR & 237467.06012 & 237467.06291 & 237467.05820 & $\cdot 0.00279$ & 0.00192 \\
\hline DYNG & ANKR & 473271.61397 & 473271.61462 & 473271.61604 & -0.00065 & $\cdot 0.00207$ \\
\hline DYNG & ISTA & 3863899.96631 & 386389.96592 & 386389.97091 & 0.00039 & -0.00460 \\
\hline DYNG & ORID & 96768.53870 & 96768.53785 & 96768.53855 & 0.00085 & 0.00015 \\
\hline DYNG & MIKL & 896666.:30607 & 896666.30143 & 896666.30537 & 0.00464 & 0.00070 \\
\hline MAT1 & DYNG & 46731.02890 & 46731.18155 & 46731.17817 & -0.15265 & -0.14927 \\
\hline MAT1 & MIIKL & 943397.33497 & 943397.48298 & 9433997.48354 & $\cdot 0.14801$ & $\cdot 0.14857$ \\
\hline NICO & ISBA & 551050.87344 & 551050.87487 & 551050.87167 & $\cdot 0.00143$ & 0.00177 \\
\hline BSHM & NICO & 36535.72353 & 36535.71680 & 365535.72104 & 0.00673 & 0.00249 \\
\hline ANKR & ARUC & 621531.73878 & 621531.73856 & 621531.74383 & 0.00022 & -0.00505 \\
\hline ISBA & ARUC & 307947.92546 & 307947.92660 & 307947.93036 & -0.00114 & -0.00490 \\
\hline DYNG & BSHM & 199268.83032 & 199268.83491 & 199268.83680 & $\cdot 0.00459$ & -0.00648 \\
\hline
\end{tabular}

Table 12: $\Delta d Y 1$ and $\Delta d Y 3$ of the network baselines

\begin{tabular}{|c|c|c|c|c|c|c|}
\hline station1 & station2 & $d Y 2(m)$ & $d Y 1(m)$ & $d Y 3(m)$ & $\Delta d Y 1=(d y 2-d y 1) \mathrm{m}$ & $\Delta d Y 3=(d y 2-d y 3) \mathrm{m}$ \\
\hline NICO & DYNG & 834683.04689 & 834683.04892 & 834683.04458 & -0.00203 & 0.00231 \\
\hline DYNG & MERS & 847533.84553 & 847533.85078 & 847533.85001 & $\cdot 0.00525$ & $\cdot 0.00448$ \\
\hline MERS & NICO & 12850.79864 & 12850.80186 & 12850.80543 & $\cdot 0.00322$ & $\cdot 0.00679$ \\
\hline NICO & ANKR & 221929.34304 & 221929.35007 & 221929.34541 & $\cdot 0.00703$ & $\cdot 0.00237$ \\
\hline DYNG & ANKR & 612753.70385 & 612753.698855 & 612753.69917 & 0.00500 & 0.00468 \\
\hline DYNG & ISTA & 295416.35473 & 295416.36630 & 295416.36593 & $\cdot 0.00157$ & $\cdot 0.00120$ \\
\hline DYNG & ORID & 331166.92723 & 331166.92556 & 331166.92366 & 0.00167 & 0.00357 \\
\hline DYNG & MIKL & 269242.04727 & 269242.05010 & 269242.04964 & $\cdot 0.00283$ & $\cdot 0.00237$ \\
\hline MAT1 & DYNG & 646380.26107 & 646380.25874 & 646380.25828 & 0.00233 & 0.00279 \\
\hline MATI & MIKL & 915622.30834 & 915622.30884 & 915622.30792 & $\cdot 0.00050$ & 0.00042 \\
\hline NiCO & ISBA & 860312.99648 & 860312.99165 & 860312.99630 & 0.00483 & 0.00018 \\
\hline BSHM & NCO & 206590.00852 & 206590,00522 & 206590.01201 & 0.00330 & $\cdot 0.00349$ \\
\hline ANKR & ARUC & 738244.87632 & 738244.87944 & 738244.87473 & -0.00312 & 0.00159 \\
\hline ISBA & ARUC & 343997.46320 & 343997.46228 & 343997.46698 & 0.00092 & $\cdot 0.00378$ \\
\hline DYNG & BSHM & 1041273.05541 & 1041273.05414 & 1041273.05659 & 0.00127 & -0.00118 \\
\hline
\end{tabular}

Table 13: $\triangle d Z 1$ and $\triangle d Z 3$ of the network baselines

\begin{tabular}{|c|c|c|c|c|c|c|}
\hline station1 & station2 & $\mathrm{d} Z 2(\mathrm{~m})$ & $d z 1(m)$ & $\mathrm{d} z 3(\mathrm{~m})$ & $\Delta d Z 1=(d Z 2-d Z 1) / m$ & $\Delta d Z 3=(d Z 2-d Z 3) \mathrm{m}$ \\
\hline NiCO & DYNG & 261847.94291 & 261847.93919 & 261847.94298 & 0.00372 & $\cdot 0.00007$ \\
\hline DYNG & MERS & 133748.78066 & 133748.77385 & 133748.77974 & 0.00681 & 0.00092 \\
\hline MERS & NCO & 128099.16225 & 128099.16534 & 128099.16324 & -0.00309 & $\cdot 0.00099$ \\
\hline NCO & ANKR & 418245.86414 & 418245.86007 & 418245.86252 & 0.00407 & 0.00162 \\
\hline DYNG & ANKR & 156397.92123 & 156397.92088 & 156397.91954 & 0.00035 & 0.00169 \\
\hline DYNG & ISTA & 258641.43196 & 258641.43521 & 258641.43105 & -0.00325 & 0.00091 \\
\hline DYNG & ORID & 260966.04824 & 260966.05196 & 260966.05097 & -0.00372 & $\cdot 0.00273$ \\
\hline DYNG & MIKL & 727143.67894 & 727143.68219 & 727143.67911 & -0.00325 & $\cdot 0.00017$ \\
\hline MAT1 & DYNG & 220655.25003 & 220655.12592 & 220655.12224 & 0.12411 & 0.12779 \\
\hline MAT1 & MIKL & 506488.42891 & 506488.55627 & 506488.55687 & -0.12736 & $\cdot 0.12796$ \\
\hline NICO & ISBA & 165084.31234 & 165084.31343 & 165084.30983 & -0.00109 & 0.00251 \\
\hline BSHM & NICO & 217279.60576 & 217279.74372 & 217279.73971 & $\cdot 0.13796$ & $\cdot 0.13395$ \\
\hline ANKR & ARUC & 34003.91870 & 34003.78756 & 34003.78383 & 0.13114 & 0.13487 \\
\hline ISBA & ARUC & 617334,09518 & 617333.96106 & 617333.95618 & 0.13412 & 0.13900 \\
\hline DYNG & BSHM & 479127.54867 & 4791277.68291 & 479127.68269 & $\cdot 0.13424$ & -0.13402 \\
\hline
\end{tabular}

These results are represented in graphic relationships to show the extent of the change in the movement of network stations, Figures $(17,18,19,20,21$ and 22).

From figures (17) and (18), we note the following; the baseline number 1 decreased $2 \mathrm{~mm}$ in its length on the day of the aftershock at $27 / 10 / 20$ in the $\mathrm{X}$ direction, but at 10/11/2017, after two weeks from the earthquake, we found that the value of $\Delta \mathrm{dX} 3$ has no change in its length, the baseline 2 have no change in $\Delta \mathrm{dX} 1$ vaue but in $\Delta \mathrm{dX} 3$ increased about $4 \mathrm{~mm}$. The baselines numbers 3,4 and 5 have a displacement values about $2 \mathrm{~mm}$ to $3 \mathrm{~mm}$. there isn't any change in length of baseline numbers 7 and 8, then a little change in baseline 11 and 14. We notice a great jump in $\Delta \mathrm{dX} 1$ values of baselines numbers 9 (MAT1-DYNG) and baseline10 (MAT1-MIKL), where the value of $\Delta \mathrm{dX} 1$ equals about $15 \mathrm{~cm}$ and $14 \mathrm{~cm}$, respectively. This indicates that these stations are the most affected by the earthquake shaking. Because of the Earth's surface still preserved the impact of the earthquake's internal forces, so this indicates the possibility of an earthquake near these two lines in this region. 


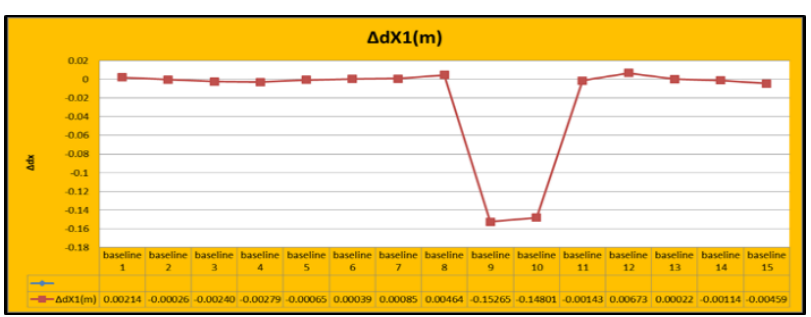

Figure 17: Diagram of all values of $\Delta \mathrm{dX} 1 \mathrm{of}$ all baselines on the day of the earthquake.

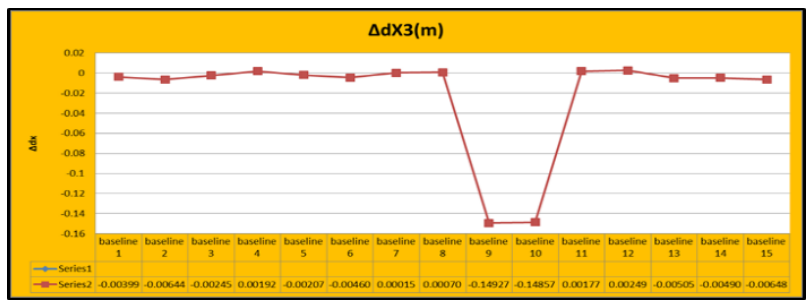

Figure 18: Diagram of all values of $\Delta d X 3$ of all baselines after the earthquake.

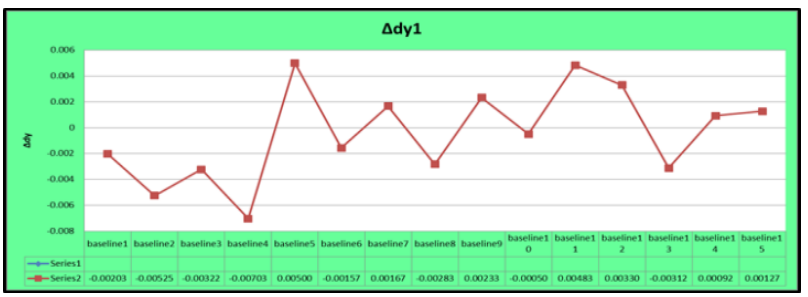

Figure 19: Diagram of all values of $\Delta d Y 1$ of all baselines.

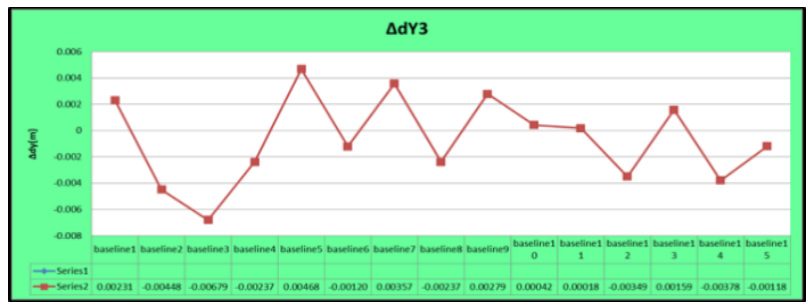

Figure 20: Diagram of all values of $\Delta \mathrm{dY} 3$ of all baselines after the earthquake.

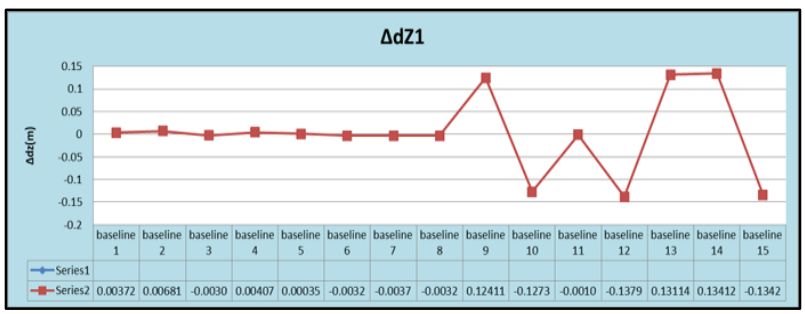

Figure 21: Diagram of all values of $\Delta \mathrm{dZ1}$ of all baselines.

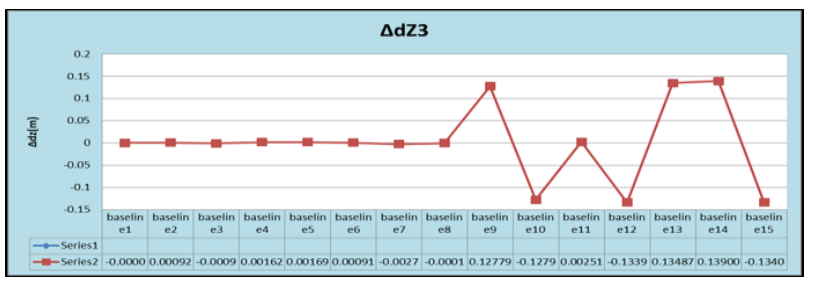

Figure 22: Diagram of all values of $\Delta \mathrm{dZ3}$ of all baselines.
For the graph of $\Delta \mathrm{dX} 1$ and $\Delta \mathrm{dX} 3$, figures $(17,18)$, we found that most values in a range of $1 \mathrm{~mm}$ to $6 \mathrm{~mm}$ as a maximum as an increase or decrease values, but two baselines number 9 and 10 have large displacement values equal about 15 centimeters, as their stations are close to the epicenter of the earthquake, so most affected.

For graphs of $\Delta \mathrm{dY} 1$ and $\Delta \mathrm{dY} 3$, we noticed that in $\Delta \mathrm{dY} 1$ values of the baselines number1,2,3,4,6, 8,10, and 13 increased about $2 \mathrm{~mm}$ to $7 \mathrm{~mm}$, and the rest of the other lengths decreased in a range of $1 \mathrm{~mm}$ to $5 \mathrm{~mm}$. At $\Delta \mathrm{dY} 3$ figure (20), we noticed that values after two weeks from the earthquake were closed together from $1 \mathrm{~mm}$ to $6 \mathrm{~mm}$ as maximum.

For values of $\Delta \mathrm{dZ}$, the $\Delta \mathrm{dZ} 1$ in the graph of Figure (21), we found that the change range from $1 \mathrm{~mm}$ to $6 \mathrm{~mm}$ as a maximum. A number of baselines increased more like baseline numbers 9,10, 12,13,14, and 15 they have displacement values about 12 to $13 \mathrm{~cm}$, which means they have the most effects of the earthquake and led to big station motions, after two weeks from the earthquake we found the values of $\Delta \mathrm{dZ} 3$ have ranged between $1 \mathrm{~mm}$ to $2 \mathrm{~mm}$, but the baselines numbers 9,10,12,13,14 and 15 increased much and to reached of $12 \mathrm{~cm}$ to $14 \mathrm{~cm}$.

\section{CONCLUSION}

This paper studies the use of the GNSS system for the detection of the displacement values of all network points surrounding the earthquake area (Aegean earthquake 2017 in turkey) and also the station displacements of the same Aegean network under the earthquake aftershock that was after three months from the Aegean earthquake. Then an evaluation of the displacements of all network baselines was made for three consecutive days, on the day before the earthquake, on the day of the earthquake, and the day after. The objective is to assess how the earthquake affects the ground station's movements and to find out the specific factors causing the changes in the magnitude of these displacements. The study also evaluates the station's height displacements caused by the earthquake. The more elements that are studied under the effect of the earthquake shaking, the more we can know the response of the ground surface and the movement of points in a better and more accurate way. Seismic monitoring was made using the global navigation satellite system (GNSS) which is considered an effective tool for natural hazard monitoring. Bernese 5.2 GNSS Software was used to obtain high-precision results of the IGS station data. This technique may be used as a tool to predict the occurrence of earthquakes in the areas which are known to be subjected to frequent earthquakes. It was also found that by increasing the monitoring periods, more accurate results may be obtained which helps in preventing considerable human and economic losses.

\section{CREDit Authorship Contribution STATEMENT}

R. Mosad: Research and analysis, Writing -original Draft Elkutb: Methodology, Software, Review, Data Curation, Supervision. A.ElHattab: Conceptualization, Methodology, Review, Supervision, M.Rabah: Conceptualization, Formal Analysis, Review, Resource. A.Elkoshy: Review-editing, Supervision, Validation, Resource. 


\section{DECLARATION OF COMPETING INTEREST}

The authors declare that they have no known competing financial interest or personal relationships that could have appeared to influence the work reported in this paper.

\section{REFERENCES}

[1] S. Gleason and, D. Gebre-Egziabher \& D. G. Egziabher "GNSS Applications and Methods". Boston, MA: Artech House, 2009.

[2] G. Beutler, A. W. Moore, and I. I. Mueller. Journal: Journal of Geodesy, Volume 83, Number 3-4, 2009, Page 297

[3] G. Beutler, J. Kouba, \& T. Springer, "Combining the orbits of the IGS Analysis Centers". Bulletin Géodésique 69, 200-222,

1995. https://doi.org/10.1007/BF00806733

[4] R. Dach, and P.Walser. "Bernese GNSS Software Version 5.2.", 2015.

[5] F. N. Teferle, E. J. Orliac and, R. M. Bingley. "An assessment of Bernese GPS software precise point positioning using IGS final products for global site velocities." GPS solutions 11.3, 2007: 205-213.

[6] "M 6.7 - 10km SSE of Bodrum, Turkey". United States Geological Survey. 21 July 2017. Retrieved 20 July 2017.

[7] N. C.T Sai and, G. W. Housner. "Calculation of surface motions of a layered half-space." Bulletin of the Seismological Society of America 60.5, 1970: 1625-1651.

[8] J. Dhanya, , M. Gade, and S. T. G. Raghukanth. "Ground motion estimation during artlthe 25th April 2015 Nepal earthquake." Acta Geodaetica et Geophysica 52.1, 2017: 69-93.

[9] Ö . Aydan, R. Ulusay, and H. Kumsar. "Seismic, ground motion and geotechnical characteristics of the 2011 Van-Erciş and Van-Edremit earthquakes of Turkey, and assessment of geotechnical damages." Bulletin of Engineering Geology and the Environment 73.2, 2014: 643-666. 